\title{
The Comparison of Somatotype Structures in Students Studying at Different Departments of Physical Education
}

\author{
Irfan Marangoz ${ }^{1}$, Sevde Mavi $\operatorname{Var}^{1}$ \\ ${ }^{1}$ Kursehir Ahi Evran University, School of Physical Education and Sports, Kursehir, Turkey \\ Correspondence: Irfan Marangoz, Kırsehir Ahi Evran University, School of Physical Education and Sports, Kırsehir, \\ Turkey.
}

Received: June 11, 2018

Accepted: June 29, $2018 \quad$ Online Published: July 18, 2018

doi:10.11114/jets.v6i9.3345

URL: https://doi.org/10.11114/jets.v6i9.3345

\begin{abstract}
This study aims to analyze the somatotype structures in students studying at different departments of physical education. A total of 300 male students (elite-sub-elite athletes) who study physical education and sports $(\mathrm{n}=100)$, coaching education $(\mathrm{n}=100)$ and sports management $(\mathrm{n}=100)$ at School of Physical Education and Sports at University of Kirsehir Ahi Evran voluntarily participated in this study. Somatotype structures were determined using Heath-Carter method and SOMATOTURK calculation program. SPSS 22.0 package program for Windows was used for correlation analysis, and the level of significance was taken as 0.05 . The results indicate that while students (elite-sub-elite athletes) participating in the study had a mesomorph structure, which is one of the most important body structure parameters for performance and characterized by a muscularity component, during early periods of their education (freshman and sophomore years), their bodies transformed into an endomorph structure, which is characterized by fat components, during later periods of their education (junior and senior years).
\end{abstract}

Keywords: somatotype structures, physical education, students

\section{Introduction}

Somatotype reveals an individual's body type. The determination of somatotype is a method used to define human physiology from different aspects in relation with body shape and composition (Eston, \& Reilly, 2009). The percentages of body components differ depending on the sport type, and influence an athlete's performance (Bektas, Koca Ozer, Gultekin, Sagir, \& Akin, 2007). Body structure and anthropometry play an important role in sports performances. Body structures which are formed by specific body movement sequences in a sport resemble each other in terms of anthropometric properties (Elliott, \& Mester, 1998). Therefore, these differences are likely to change performance limits of an athlete (Karakus, \& Kilinc, 2006; Uetake, \& Ohtsuki, 1993). It is necessary to determine the effect of body structure on the performance in order to test the performance limits. Thus, there is no doubt that the determination of somatotype structures, which play a decisive role in sports performance, will contribute and bring a new perspective to the sports science.

\section{Material and Methods}

This study focuses on the analysis of somatotype structures in students studying at different departments of physical education. A total of 300 male students (elite-sub-elite athletes) who study physical education and sports ( $\mathrm{n}=100)$, coaching education $(n=100)$ and sports management $(n=100)$ at School of Physical Education and Sports at University of Kirsehir Ahi Evran voluntarily participated in this study. Somatotype structures of the athletes (endomorph, mesomorph and ectomorph) were determined using Heath-Carter method. Endomorph is a component characterized by a round body shape. It can defined as the "fat" component of a body. Mesomorph is characterized by a slim and square body shape with strong and visibly muscularity. The bones are surrounded by big and thick muscles. Ectomorph is represented by a slim and thin body and defines a fat-free body structure (Fox, Bowers, \& Foss, 2012).

\subsection{Determination of Somatotypes}

The somatotype values of the participants were determined using Heath Carter method. Thanks to factor analysis, this method can easily determine somatotypes among different anthropometric measurements without needing images. It is based on tables calculated using statistical analyses on some measurements which belong to individuals whose 
somatotypes are determined using Sheldon Atlas. These tables formulate triceps, subscapula and suprailiac skinfold thickness in order to calculate endomorph points (Formula 1). Humerus epicondyle breadth, femur epicondyle breadth, biceps during flexion, calf circumference, triceps skinfold thickness and medial calf skinfold thickness are measured in order to calculate mesomorph points (Formula 2). Height and weight measurements are used for ectomorph points (Formula 3) (Carter, \& Heath, 1971; Carter, \& Heath 1990; Ross, \& Marfell-Jones, 1991; Carter, 2002). In addition, "SOMATOTURK" program developed by Marangoz \& Ozbalci (2017) was used for calculations.

2.1.1 Determination of Endomorph

$A=$ triceps + subscapular + suprailiac

$B=(170.18 /$ height $)$ (Adjustment coefficient for height)

Adjusted sum $X=A . B$

$$
\text { Endomorph }=-0.7182+0.1451(X)-0.00068(X 2)+0.0000014(X 3)
$$

\subsubsection{Determination of Mesomorph}

$$
\text { Mesomorph }=(0.858 H B+0.601 F B+0.188 C A G+0.161 C C G)-(0.131 H)+4.5
$$

HB: Humerus breadth $(\mathrm{cm})$

FB: Femur breadth $(\mathrm{cm})$

CAG: Arm circumference during flexion - Triceps skinfold /10

CCG: Maximal calf circumference - Calf skinfold /10

$\mathrm{H}$ : Height (cm)

\subsubsection{Determination of Ectomorph}

Height and weight are calculated in $\mathrm{cm}$ and $\mathrm{kg}$, respectively. Height is divided by the cube root of weight to calculate HWR (HWR=height/cube root of weight). Ectomorph is calculated based on HWR value using one of the formulas below:

$$
\text { IF HWR } \geq 40.75 \text {, Ectomorph }=0.732 \times \text { HWR }-28.58
$$

IF $38.25<$ HWR $<40.75$, Ectomorph $=0.463 \times$ HWR -17.63

IF HWR $\leq 38.25$, Ectomorph $=0.1$

\subsubsection{Somatotype Categories}

13 somatotypes which are categorized based on their areas on the somatochart can be defined as follows:

Central: The difference between one component and other two components is not higher than one unit.

Balanced Endomorph: While it is dominated by endomorph, mesomorph and endomorph are either equal or do not differ by more than a one-half unit.

Mesomorphic Endomorph: It is dominated by endomorph, and mesomorph is greater than ectomorph.

Mesomorph Endomorph: Endomorph and mesomorph are either equal or do not differ by more than a one-half unit, and ectomorph is smaller.

Endomorphic Mesomorph: It is dominated by mesomorph, and endomorph is greater than ectomorph.

Balanced Mesomorph: While it is dominated by mesomorph, endomorph and ectomorph are either equal or do not differ by more than a one-half unit.

Ectomorphic Mesomorph: It is dominated by mesomorph, and ectomorph is greater than endomorph.

Mesomorph Ectomorph: Mesomorph and ectomorph are either equal or do not differ by more than a one-half unit, and endomorph is smaller.

Mesomorphic Ectomorph: It is dominated by ectomorph, and mesomorph is greater than endomorph.

Balanced Ectomorph: While it is dominated by ectomorph, endomorph and mesomorph are either equal or do not differ by more than a one-half unit.

Endomorphic Mesomorph: While it is dominated by ectomorph, endomorph is greater than mesomorph.

Endomorph Ectomorph: Endomorph and ectomorph are either equal or do not differ by more than a one-half unit. Mesomorph is lower. 
Ectomorphic Endomorph: While it is dominated by endomorph, ectomorph is greater than mesomorph (Carter, 2002; Duquet, \& Carter, 2009).

\subsection{Statistical Analyses}

SPSS 22.0 package program for Windows was used for descriptive statistics, Spearman correlation analysis and chi-square analysis, and the level of significance was taken as 0.05 .

\section{Findings}

Table 1. Descriptive statistics of the study

\begin{tabular}{|c|c|c|c|c|c|}
\hline & & Age & Weight & Height & Somatotype \\
\hline & $\mathrm{N}$ & $\mathrm{x} \pm \mathrm{sd}$ & $\mathrm{x} \pm \mathrm{sd}$ & $\mathrm{x} \pm \mathrm{sd}$ & EndoMesoEcto \\
\hline nan & \multicolumn{5}{|c|}{$2520.45 \pm 1.5668 .14 \pm 8.10173 .00 \pm 3.122 .744 .76$ 2.48Balanced Mesomorph } \\
\hline ore & \multicolumn{5}{|c|}{$2521.36 \pm 2.8068 .50 \pm 6.52$ 175.15 \pm 4.203 .093 .88 2.99Balanced Mesomorph } \\
\hline & \multicolumn{5}{|c|}{$2522.30 \pm 0.1374 .30 \pm 12.50174 .50 \pm 4.303 .504 .832,10$ Mesomorph Endomorph } \\
\hline & \multicolumn{5}{|c|}{$2521.95 \pm 1.1074 .22 \pm 8.50174 .40 \pm 5.153 .454 .75$ 1.85Endo Mesomorph } \\
\hline & \multicolumn{5}{|c|}{$2519.80 \pm 2.5075 .20 \pm 6.50170 .10 \pm 6.503 .103 .88$ 2.90Balanced Mesomorph } \\
\hline & \multicolumn{5}{|c|}{$2520.85 \pm 1.5572 .30 \pm 7.50178 .50 \pm 5.203 .53$ 3.62 2.63Mesomorph Endomorph } \\
\hline & \multicolumn{5}{|c|}{$2523.70 \pm 5.3071 .52 \pm 9.50173 .90 \pm 7.203 .12$ 4.29 2.13Endo Mesomorph } \\
\hline & \multicolumn{5}{|c|}{ 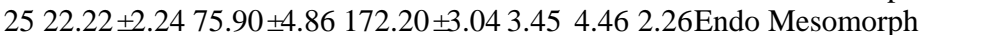 } \\
\hline & \multicolumn{5}{|c|}{$2520.35 \pm 6.2068 .45 \pm 9.50174 .30 \pm 4.503 .363 .89$ 3,10Balanced Mesomorph } \\
\hline & \multicolumn{5}{|c|}{25 21.15 $\pm 2.0670 .20 \pm 7.60174 .84 \pm 4.203,103.79$ 2,98Balanced Mesomorph } \\
\hline & \multicolumn{5}{|c|}{$2522.10 \pm 1.1573 .07 \pm 8.27$ 179.11 \pm 5.263 .20 4.50 2.30Mesomorph Endomorph } \\
\hline ports Management Senior & \multicolumn{5}{|c|}{$2522.20 \pm 2.0175 .21 \pm 8.25$ 172.34 3.213 .404 .30 2.20Endo Mesomorph } \\
\hline
\end{tabular}

Table 2. The comparison of somatotype structures among groups and within groups

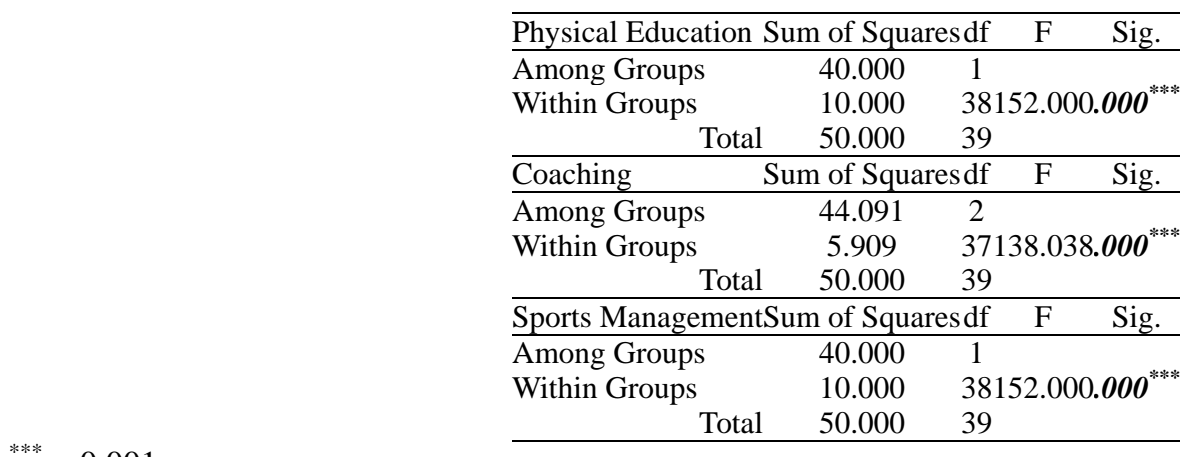

$\mathrm{p}<0.001$

Table 3. The comparison of chi-square analysis for different variables

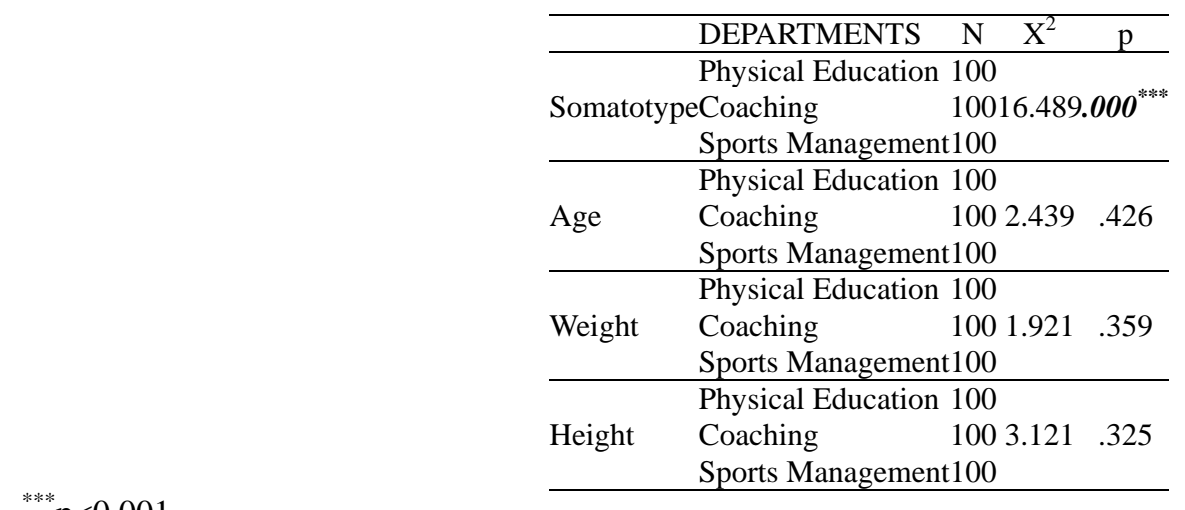

\section{$\mathrm{p}<0.001$}

The complex structure of sports performance stems from the high number and diversity of related factors, which may influence the performance positively and negatively. They are divided into two groups as internal and external factors. Internal factors are elements in a human body which are partially hereditary, can vary with small changes within time and are impossible or too difficult to change through external interventions. Age, gender and anatomic structure are among leading internal factors. External factors, on the other hand, as its name implies, do not depend on human body and structure and thus can indirectly influence sports performance through physical and psychic components. Therefore, 
it is more reasonable and easier to make changes on the external factors to improve sports performance for healthier and more effective results (Bayraktar, \& Kurtoglu 2004).

Various studies indicate that some athletic traits particularly decline due to ageing, which is one of the internal factors. For instance, sprinters lose a considerable portion of their speed and reaction time, and it takes them longer to touch the ground while falling, which is a direct negative influence on their running times (Korhonen, Mero, \& Suominen, 2003). Isokinetic knee extension/flexion strength test results of elite football players and specific test results of oarsmen demonstrated that strength and endurance-related performance values decline in proportion to ageing (Galloway, Kadoko, \& Jokl, 2002).

Gualdi-Russo and Zaccani (2001) was researched somatotype of 234 male and 244 female elite Italian volleyball players in relation to their different game roles. Somatotypes of athletes were estimated with the Heath-Carter method. As a result of the study the physique of athletes in the A1 league was characterized by higher ectomorphy and lower endomorphy and mesomorphy. Besides the mesomorphic component was maximal in setters, while the ectomorphic component was maximal in centres.

Pieter and Bercades (2009) studied about somatotypes of elite adult combative sport athletes. Subjects were members of the Philippine national senior teams in karate and pencak silat (30 men, 10 women) and fencing (6 women). The Heath-Carter somatotype method was used to assess the physiques of the athletes. When comparing the Filipino male elite karateka and silat athletes in the study, there was no statistical difference in somatotype. In the females, on the other hand, the karateka were significantly less mesomorphic than the fencers. The female silat athletes were more endomorphic than the karateka, although statistically not significant. However, the latter scored higher in endomorphy and mesomorphy, while the karateka were more ectomorphic.

It was found out in the present study that physical education and sports students (elite-sub-elite athletes) participating in the study were categorized as balanced mesomorph during their freshman and sophomore years, while they were categorized as mesomorph endomorph and endo mesomorph during their junior and senior years, respectively. Coaching education students (elite-sub-elite athletes) were categorized as balanced mesomorph and mesomorph endomorph during their freshman and sophomore years, respectively, while they were categorized as endo mesomorph during their junior and senior years. Finally, sports management students (elite-sub-elite athletes) were categorized as balanced mesomorph during their freshman and sophomore years, while they were categorized as mesomorph endomorph and endo mesomorph during their junior and senior years, respectively.

In conclusion, while students (elite-sub-elite athletes) participating in the study had a mesomorph structure, which is one of the most important body structure parameters for performance and characterized by a muscularity component, during early periods of their education (freshman and sophomore years), their bodies transformed into an endomorph structure, which is characterized by fat components, during later periods of their education (junior and senior years). This can be associated with some declines in athletic traits of the students (elite-sub-elite athletes) due their lack of goal setting in their discipline, which unsurprisingly resulted in an endomorph structure with dominant fat components. Thus, their sports performances dramatically decreased.

\section{References}

Bayraktar, B., \& Kurtoglu, M. (2004). Sports performance and performance improvement methods. In: T Atasu, I Yucesir (Eds.): Doping and Football Performance Improvement Methods. Istanbul: TFF Publications.

Bektas, Y., Koca, O. B., Gultekin, T., Sagir, M., \& Akin, G. (2007). Anthropometric Characteristics of Female Basketball Players: Somatotype, Journal of Physical Education and Sports Science, 1(2).

Carter, J. E. L. (2002). The Heath-Carter Anthropometric Somatotype-Instruction Manual. San Diego, USA.

Carter, J. E. L., \& Heath, B. H. (1971). Somatotype Methodology and Kinesiology Research. Kinesiology Review, 10-19.

Carter, J. E. L., \& Heath, B. H. (1990). Somatotyping - Development and Applications. New York: Cambridge University Press.

Duquet, W., \& Carter, J. E. L. (2009). Somatotyping, In: Somatotyping, Kinanthropometry and Exercise Physiology Laboratory Manual Tests, Procedures and Data (Third Edition) Volume One: Anthropometry, Routledge Taylor and Francis Group, London.

Elliott, B., \& Mester, J. (1998). Training in sport: applying sport science. John Wiley \& Sons Ltd. England.

Eston, R., \& Reilly, T. (2009). Somatotyping, Kinanthropometry and Exercise Physiology Laboratory Manual Tests, Procedures and Data Third Edition Volume One: Anthropometry, Routledge Taylor and Francis Group, London. 
Fox, E. L., Bowers, R. W., \& Foss, M. L. (2012). The Physiological Basis of Physical Education, Ed: Mesut Cerit, Spor Publishing, Ankara.

Galloway, M. T., Kadoko, R., \& Jokl, P. (2002). Effect of aging on male and female master athletes' performance in strength versus endurance activities. American Journal of Orthopedics (Belle Mead, NJ), 31(2), 93-98.

Gualdi-Russo, E., \& Zaccagni, L. (2001). Somatotype, role and performance in elite volleyball players Journal of Sports Medicine and Physical Fitness, 41(2), 256-62.

Karakus, S., \& Kilinc, F. (2006). Posture and Sportive Performance. Kastamonu Education Journal, 14(1), 309-322.

Korhonen, M. T., Mero, A., \& Suominen, H. (2003). Age-related differences in 100-m sprint performance in male and female master runners. Medicine \& Science in Sports \& Exercise, 35(8), 1419-1428. https://doi.org/10.1249/01.MSS.0000079080.15333.CA

Marangoz, I., \& Ozbalc1, U. (2017). Somatotype calculation program (SOMATOTURK), The Journal of Academic Social Science, 47(5), 288-293. https://doi.org/10.16992/ASOS.12307

Pieter, W., \& Bercades, L. T. (2009). Somatotypes of national elite combative sport athletes. Brazilian Journal of Biomotricity, 3(1), 21-30.

Ross, W. D., \& Marfell-Jones, M. J. (1991). Kinanthropometry. In MacDougall, DJ., Wenger AH \& Green H J. (Eds). Physiological Testing of the High-Performance Athlete. Illinois: Human Kinetics Books.

Uetake, T., \& Ohtsuki, F. (1993). Sagittal configuration of spinal curvature line in sportsmen using Moire technique. Okajimas Folia Anat. Jpn., 70(2-3), 91-103. https://doi.org/10.2535/ofaj1936.70.2-3_91

\section{Copyrights}

Copyright for this article is retained by the author(s), with first publication rights granted to the journal.

This is an open-access article distributed under the terms and conditions of the Creative Commons Attribution license which permits unrestricted use, distribution, and reproduction in any medium, provided the original work is properly cited. 